\title{
Genetic polymorphisms in the TERT gene and susceptibility to non-small cell lung cancer in a Chinese Han population
}

This article was published in the following Dove Press journal: Cancer Management and Research

\author{
Chuanyin $\mathrm{Li}^{1, *}$ \\ Xiaona Wangl,* \\ Yingfu $\mathrm{Li}^{2}$ \\ Xinwen Zhang' \\ Mingbo Sun' \\ Shuyuan Liu' \\ Le Sun ${ }^{3}$ \\ Li Shi' \\ Yufeng Yao'
}

'Institute of Medical Biology, Chinese Academy of Medical Sciences \& Peking Union Medical College, Kunming 650II8, China; ${ }^{2}$ Department of Geriatrics, The No.I Affiliated Hospital of Kunming Medical University, Kunming 650032, China; ${ }^{3}$ Kunming Medical University, Kunming 650032, China

*These authors contributed equally to this work
Correspondence: Li Shi; Yufeng Yao Institute of Medical Biology, Chinese Academy of Medical Sciences \& Peking Union Medical College, 935 jiaoling Road, Kunming 6501 18, Yunnan, China

Tel +86 87I 68335632

Fax +86 87| 68I8 |483

Email shili.imb@gmail.com;

yufeng_yao@imbcams.com.cn
Background: Recent studies have revealed that the TERT gene plays crucial roles in cancer initiation and development. Genome-wide analysis studies and case-control studies have demonstrated that polymorphisms in the TERT gene are associated with various cancers.

Materials and methods: In the current study, we analyzed the associations of eight single nucleotide polymorphisms (SNPs) in the TERT gene with non-small cell lung cancer (NSCLC) in a Chinese Han population. A total of 467 NSCLC patients and 526 healthy individuals were recruited for SNP genotyping using a TaqMan assay.

Results: Our results revealed that the allelic frequencies of rs2853677 and rs2853691 were significantly different between the NSCLC and control groups ( $P=0.004$ and 0.001 , respectively). Moreover, the $\mathrm{T}$ allele of rs 2853677 and the A allele of rs2853691 might be the protective factors against NSCLC $(\mathrm{OR}=0.766$; 95\%CI: $0.639-0.918$ and $\mathrm{OR}=0.714 ; 95 \% \mathrm{CI}$ : $0.584-0.875$, respectively). Additionally, stratified association analysis of the eight SNPs with the different pathological NSCLC stages (I+II and III+IV) and different pathological types (adenocarcinoma and squamous cell carcinoma) revealed that none of the SNPs were significantly different between patients with different pathological stages and pathological types.

Conclusion: Our results indicated that rs2853677 and rs2853691 in the TERT gene might be associated with NSCLC in this Chinese Han population.

Keywords: TERT gene, polymorphisms, lung cancer, Chinese Han population

\section{Introduction}

Lung cancer is the most common cancer and is the leading cause of cancer death worldwide. ${ }^{1}$ Lung cancer can be subdivided into small cell lung cancer and non-small cell lung cancer (NSCLC). Despite the recent advances in early detection and treatment, the 5 -year survival rate for lung cancer is below $15 \%$, which indicates a poor prognosis. ${ }^{2}$ NSCLC accounts for more than $80 \%$ of lung cancers. ${ }^{3}$ Recently, studies have demonstrated that genetic factors, in addition to environmental factors, play important roles in the initiation and development of NSCLC. To date, genome-wide association studies (GWAS) have confirmed an underlying genetic contribution to lung cancer risk. ${ }^{4-6}$

Telomeres are sequences that cap the ends of chromosomes in eukaryotes and shorten with every successive mitotic cell division, which leads to replicative senescence. A minimal length of telomeric DNA is important for maintaining proper telomeric structure to protect chromosomes. ${ }^{7}$ However, gradual attrition has been found to occur in both proliferative and non-proliferative tissues as they age. ${ }^{8,9}$ This process is quintessential to the natural ageing process due to the limitations of telomerase, which 
is essential for the maintenance of the telomere. ${ }^{10}$ However, the telomeres of cancer cells can be maintained throughout infinite division through telomerase-sustaining expression. In this manner, telomerase can promote tumor progression by ensuring the maintenance of telomeres above a critically short length to avoid cellular senescence and apoptosis.

Telomerase is an RNA-dependent DNA polymerase that is comprised of a catalytic subunit, which is encoded by the TERT gene, and an RNA component that is transcribed from the telomerase RNA component (TERC). ${ }^{11}$ Studies have identified the deregulation of telomerase as a hallmark of over $90 \%$ of human cancers that are associated with an upregulation of TERT. ${ }^{12-14}$ The upregulation of TERT expression has consistently been demonstrated to be one of the fundamental requirements for cellular transformation. ${ }^{15,16}$ The human TERT gene is located on 5p15.33 and consists of 16 exons and 15 introns that span over $40 \mathrm{~kb}$ in length. Studies have described mutations that can increase the transcriptional activity of the TERT gene promoter and thus may promote cancer progression. ${ }^{17,18}$ Moreover, genome-wide analysis studies and case-control studies have demonstrated that polymorphisms in the TERT gene are associated with various cancers, such as skin cancer, colorectal cancer, and breast cancer. ${ }^{19-23}$ In the current study, we investigated the associations of eight single nucleotide polymorphisms (SNPs) in the TERT gene with NSCLC in a Chinese Han population.

\section{Materials and methods}

\section{Ethics statement}

The protocols for the current study were in accordance with the Declaration of Helsinki and were approved by the Ethics Committees of the No.1 Affiliated Hospital of Kunming Medical University. All participants provided written informed consent.

\section{Subjects}

Four hundred and sixty-seven patients (315 males and 152 females) with NSCLC were recruited from the No.1 Affiliated Hospital of Kunming Medical University from July 2012 to May 2014. Subjects with oncotherapy histories, other cancers, hypertension, coronary heart disease, and diabetes were excluded from the current study. The pathological cancer stages were determined according to the International System for Staging Lung Cancer. ${ }^{24}$ In the current study, 73 patients were in stage I, 78 patients were in stage II, 165 patients were in stage III, and 151 patients were in stage IV. The histological type of NSCLC was identified according to the World Health Organization 2004 classifications. ${ }^{25}$ During the same time period, 526 healthy individuals ( 375 males and 151 females) were recruited from the same hospital from a routine health check-up population. The clinical characteristics, including gender, age, and histological types of lung cancer, were collected. Because the subjects with a family history of cancer were excluded from the control group, individuals with a family history of cancer were also excluded from the NSCLC group. All participants self-reported as Han and lived roughly within the Yunnan Province of Southwest China.

\section{SNP selection and genotyping}

In the current study, we selected eight SNPs (rs2736098, rs2853676, rs2853677, rs10069690, rs2075786, rs2736114, rs2736122, and rs2853691) in the TERT gene from the reports focusing on the association studies of polymorphisms in TERT gene through searching PubMed; SNPs with a minor allele frequency higher than $5 \%$ in Chinese population were included according to the 1000 genome data. SNP rs 2736098 is located in exon 2, rs2853676 and rs2853677 are located in intron 2, rs10069690 is located in intron 4, rs2075786 and rs2736114 are located in intron 10, rs2736122 is located in intron 13, and rs2853691 is located in the near gene-3 region. Five milliliters of the whole blood of each subject were extracted. Next, the genomic DNA was extracted from the peripheral lymphocytes using the QIAamp Blood Mini Kit (Qiagen NV, Venlo, the Netherlands). The eight SNPs in the TERT gene were selected and genotyped using TaqMan assays. The TaqMan assays (primers and probes) were designed and produced by Thermo Fisher Scientific (Waltham, MA, USA). The assay ID for each of the SNPs was as follows: rs2075786 (C_15824034_10), rs2736114 (C___1844035_20), rs 10069690 (C__30322061_10), rs $2736098\left(\mathrm{C}_{-} 26414916_{-} 20\right)$, rs 2736122 (C_-_1844039_10), rs2853676 (C_-_8773291_20), rs2853677 ( $\left.\mathrm{C}_{--\_} 1844008_{-} 10\right)$, and rs2853691 (C__1844041_10). A $5 \mu \mathrm{L}$ reaction system comprised of $2.5 \mu \mathrm{L} 2 \times$ TaqMan Master Mix, $0.125 \mu \mathrm{L} 40 \times$ primer and TaqMan Probe (FAM VIC) dye mix, $1.375 \mu \mathrm{L} \mathrm{ddH}_{2} \mathrm{O}$, and $1 \mu \mathrm{L}$ template DNA (substituted with the equivalent $\mathrm{ddH}_{2} \mathrm{O}$ volume in the negative controls) was amplified in a 384-well plate using the following PCR cycle conditions: $95^{\circ} \mathrm{C}$ for $10 \mathrm{~min}$; and a PCR stage at $92^{\circ} \mathrm{C}$ for $10 \mathrm{~s}$ and $60^{\circ} \mathrm{C}$ for $1 \mathrm{~min}$, repeated for 40 cycles. The data acquisition was performed using a QuantStudio 6 Flex Fast Real-Time PCR system, and the data were further analyzed with the QuantStudio ${ }^{\mathrm{TM}}$ realtime PCR software (Thermo Fisher Scientific). Samples with each genotype of the eight SNPs were sequenced to evaluate the accuracy of the SNP genotyping using the TaqMan assay. 


\section{Statistical analysis}

The statistical analyses were conducted using Microsoft Excel software and the SPSS 19.0 statistical package (IBM Corporation, Armonk, NY, USA). The Hardy-Weinberg equilibrium (HWE) was tested to evaluate the representativeness of the NSCLC and control groups. The effects of the polymorphisms on the risk of NSCLC are expressed as ORs with the $95 \%$ CIs, which were calculated using logistic regression analysis with adjustments for age and gender. The linkage equilibrium (LD) and haplotype frequencies were calculated based on the genotyping results using the expectation-maximization algorithm of the SHEsis software. ${ }^{26,27} \mathrm{~A} D^{\prime}$ value $>0.8$ indicated the existence of different loci in the LD. The differences in the haplotypes between the case and control groups were determined with $\chi^{2}$ tests with Bonferroni corrections for multiple testing. The association of each genotype with the risk of NSCLC was evaluated using the inheritance model analysis of the SNPstats software. ${ }^{28}$ The following five inheritance models were analyzed: codominant, dominant, recessive, overdominant, and log-additive. ${ }^{28}$ The Akaike information criterion (AIC) and Bayesian information criterion (BIC) were calculated to determine the best fit model for each SNP. The sample size and the statistical power was calculated using "Power and Sample Size" program. ${ }^{29}$ Bonferroni corrections were applied to correct for multiple comparisons, and the threshold for statistical significance was set at $P<(0.05 / \mathrm{n})$.

\section{Results}

\section{Subject characteristics}

The clinical characteristics of the subjects are presented in Table 1 . Neither age nor gender differed significantly between the NSCLC and control groups $(P>0.05)$. There were 285

Table I Clinical characteristics of the subjects enrolled in the present study

\begin{tabular}{llll}
\hline Characteristics & NSCLC & Control & P-value \\
\hline N & 467 & 526 & \\
Age (years) & $56.02 \pm 10.76$ & $54.94 \pm 9.45$ & 0.095 \\
Gender (M/F) & $315 / 152$ & $375 / 15 \mathrm{I}$ & 0.191 \\
Adenocarcinoma & 285 & & \\
Squamous cell carcinoma & 172 & & \\
Adenocarcinoma and & 10 & & \\
squamous cell carcinoma & & & \\
Clinical stage & & & \\
I & 73 & & \\
II & 78 & & \\
III & 165 & & \\
IV & 151 & \\
\hline Abbriation & & & \\
\hline
\end{tabular}

Abbreviation: NSCLC, non-small cell lung cancer.
NSCLC patients with adenocarcinomas (ACs), 172 patients with squamous cell carcinomas (SCCs), and ten patients with ACs and SCCs (AC+SCC). Seventy-three patients were in stage I, 78 patients were in stage II, 165 patients were in stage III, and 151 patients were in stage IV.

\section{Associations of the eight SNPs in the TERT gene with NSCLC}

The allelic and genotypic distribution characteristics of the eight SNPs between the NSCLC and control groups are presented in Table 2. The NSCLC and control subjects were in HWE for each of the eight SNPs in the current study $(P>0.05)$. Logistic regression analysis (adjusted for age and gender) indicated that the allelic frequency of the rs 2853677 SNP and the allelic and genotypic frequencies of the rs2853691 SNP differed significantly between the NSCLC and control groups $(P<0.006)$. The $\mathrm{T}$ allele of rs 2853677 and the A allele of rs 2853691 might be protective factors against NSCLC (OR $=0.766$; 95\%CI: $0.639-0.918$ and $\mathrm{OR}=0.714$; 95\%CI: 0.584-0.875, respectively). The other six SNPs exhibited no associations with NSCLC $(P>0.006)$.

\section{Model of inheritance analyses of the associations of the eight SNPs in the TERT gene with NSCLC}

Inheritance analysis was used to evaluate the associations of the SNP genotypes with the NSCLC groups. The AIC and BIC were simultaneously calculated to determine the best fit inheritance model with the smallest AIC and BIC values. The results revealed that the best inheritance model for both rs2853677 and rs2853691 was the log-additive model ( $P=0.003$ and 0.001 , respectively) after correction for age and gender (Tables 3 and 4). In this model, the 2TT+CT of rs 2853677 plays a protective role against $\mathrm{NSCLC}(\mathrm{OR}=0.75$; 95\%CI: $0.62-0.91)$, and this finding is similar to that for the $2 \mathrm{AA}+\mathrm{AG}$ of $\mathrm{rs} 2853691$ (OR=0.72; 95\% CI: 0.59-0.88). Additional results (data not shown) indicate that no significant differences were found in the distributions of the other six SNPs between the NSCLC and control groups in the model of inheritance analysis $(P>0.006)$.

\section{LD and haplotype analysis of the eight SNPs in the TERT gene}

Table 5 lists the linkage relationship of the SNPs. The LD values $\left(D^{\prime}\right)$ between rs 2853676 and rs 2853677 , and between rs2075786, 2736114, and 2736122 were all over 0.800 . According to the LD results, we constructed the haplotypes 
Table 2 The association analysis between the eight SNPs in TERT gene and NSCLC (after adjusting for gender and age)

\begin{tabular}{|c|c|c|c|c|c|c|c|c|c|c|}
\hline \multirow{2}{*}{$\frac{\text { SNPs }}{r s 2736098}$} & \multicolumn{3}{|c|}{ Genotypes (n, \%) } & \multirow[t]{2}{*}{$\chi^{2}$} & \multirow[t]{2}{*}{$P$-value } & \multicolumn{2}{|c|}{ Alleles (n, \%) } & \multirow[t]{2}{*}{$\chi^{2}$} & \multirow[t]{2}{*}{$P$-value* } & \multirow[t]{2}{*}{ OR (95\% Cl) } \\
\hline & $\mathrm{C} / \mathrm{C}$ & $\mathrm{C} / \mathrm{T}$ & $\mathrm{T} / \mathrm{T}$ & & & $\mathrm{C}$ & $\mathrm{T}$ & & & \\
\hline NSCLC & $167(0.358)$ & $234(0.50 I)$ & $66(0.14 I)$ & 0.610 & 0.737 & $568(0.608)$ & $366(0.392)$ & 0.562 & 0.445 & $0.932(0.777-1.117)$ \\
\hline Control & $198(0.376)$ & $261(0.496)$ & $67(0.127)$ & & & $657(0.625)$ & $395(0.375)$ & & & \\
\hline rs2853676 & $\mathrm{C} / \mathrm{C}$ & $\mathrm{C} / \mathrm{T}$ & $\mathrm{T} / \mathrm{T}$ & & & $\mathrm{C}$ & $\mathrm{T}$ & & & \\
\hline NSCLC & $312(0.668)$ & I $33(0.285)$ & $22(0.047)$ & $0.36 \mathrm{I}$ & 0.835 & $757(0.810)$ & $177(0.190)$ & 0.385 & 0.563 & $0.935(0.744-1.174)$ \\
\hline Control & $360(0.684)$ & $144(0.274)$ & $22(0.042)$ & & & $864(0.82 I)$ & $188(0.179)$ & & & \\
\hline rs2853677 & $\mathrm{T} / \mathrm{T}$ & $\mathrm{T} / \mathrm{C}$ & $\mathrm{C} / \mathrm{C}$ & & & $\mathrm{T}$ & $\mathrm{C}$ & & & \\
\hline NSCLC & $143(0.306)$ & $246(0.527)$ & $78(0.167)$ & 9.204 & 0.010 & $532(0.570)$ & $402(0.430)$ & 8.587 & 0.004 & $0.766(0.639-0.918)$ \\
\hline Control & $203(0.386)$ & $261(0.496)$ & $62(0.118)$ & & & $667(0.634)$ & $385(0.366)$ & & & \\
\hline rs 10069690 & $\mathrm{C} / \mathrm{C}$ & $\mathrm{C} / \mathrm{T}$ & $\mathrm{T} / \mathrm{T}$ & & & $\mathrm{C}$ & $\mathrm{T}$ & & & \\
\hline NSCLC & $294(0.630)$ & $160(0.343)$ & $13(0.028)$ & 0.017 & 0.991 & $748(0.80 I)$ & $186(0.199)$ & 0.003 & 0.980 & $1.003(0.803-1.252)$ \\
\hline Control & $332(0.632)$ & $178(0.339)$ & $15(0.029)$ & & & $842(0.802)$ & $208(0.198)$ & & & \\
\hline rs2075786 & $\mathrm{A} / \mathrm{A}$ & $A / G$ & $\mathrm{G} / \mathrm{G}$ & & & A & G & & & \\
\hline NSCLC & $319(0.683)$ & I $32(0.283)$ & $16(0.034)$ & 1.070 & 0.586 & $770(0.824)$ & $164(0.176)$ & 0.992 & 0.292 & $1.131(0.900-1.421)$ \\
\hline Control & $343(0.652)$ & $163(0.310)$ & $20(0.038)$ & & & $849(0.807)$ & $203(0.193)$ & & & \\
\hline rs2736II4 & $\mathrm{C} / \mathrm{C}$ & $\mathrm{C} / \mathrm{T}$ & $\mathrm{T} / \mathrm{T}$ & & & $\mathrm{C}$ & $\mathrm{T}$ & & & \\
\hline NSCLC & $415(0.889)$ & $50(0.107)$ & $2(0.004)$ & 3.962 & 0.138 & $880(0.942)$ & $54(0.058)$ & 4.015 & 0.036 & $1.46 \mathrm{I}(1.025-2.082)$ \\
\hline Control & $445(0.846)$ & $77(0.146)$ & $4(0.008)$ & & & $967(0.919)$ & $85(0.081)$ & & & \\
\hline rs2736I22 & $\mathrm{A} / \mathrm{A}$ & $\mathrm{A} / \mathrm{G}$ & $\mathrm{G} / \mathrm{G}$ & & & A & G & & & \\
\hline NSCLC & $5(0.01 \mathrm{I})$ & $58(0.124)$ & $404(0.865)$ & 0.139 & 0.933 & $68(0.073)$ & $866(0.927)$ & 0.038 & 0.783 & $\mathrm{I} .049(0.748-\mathrm{I} .470)$ \\
\hline Control & $5(0.010)$ & $69(0.131)$ & $452(0.859)$ & & & $79(0.075)$ & $973(0.925)$ & & & \\
\hline rs285369l & $\mathrm{A} / \mathrm{A}$ & $\mathrm{A} / \mathrm{G}$ & $\mathrm{G} / \mathrm{G}$ & & & A & $\mathrm{G}$ & & & \\
\hline NSCLC & $242(0.518)$ & I $78(0.38 \mathrm{I})$ & $47(0.101)$ & 11.198 & 0.004 & $662(0.709)$ & $272(0.291)$ & 10.622 & 0.001 & $0.714(0.584-0.875)$ \\
\hline Control & $313(0.595)$ & $186(0.354)$ & $27(0.05 \mathrm{I})$ & & & $812(0.772)$ & $240(0.228)$ & & & \\
\hline
\end{tabular}

Note: *Statistically significant threshold was set at $P<0.006(0.05 / n, n=8)$ determined by Bonferroni correction.

Abbreviations: SNPs, single nucleotide polymorphisms; NSCLC, non-small cell lung cancer.

Table 3 Different inheritance model analysis of rs2853677 in TERT gene between NSCLC and control groups (after adjusting for gender and age)

\begin{tabular}{|c|c|c|c|c|c|c|c|}
\hline Models & Genotypes & $\operatorname{NSCLC}(n, \%)$ & Control (n, \%) & OR $(95 \% \mathrm{CI})$ & $P$-value* & AIC & BIC \\
\hline \multirow[t]{3}{*}{ Codominant } & $\mathrm{T} / \mathrm{T}$ & $143(30.6 \%)$ & $203(38.6 \%)$ & 1 & 0.011 & 1369.2 & 1393.7 \\
\hline & $\mathrm{T} / \mathrm{C}$ & $246(52.7 \%)$ & $26 I(49.6 \%)$ & $0.74(0.56-0.98)$ & & & \\
\hline & $\mathrm{C} / \mathrm{C}$ & $78(16.7 \%)$ & $62(11.8 \%)$ & $0.57(0.38-0.84)$ & & & \\
\hline \multirow[t]{2}{*}{ Dominant } & $\mathrm{T} / \mathrm{T}$ & $143(30.6 \%)$ & $203(38.6 \%)$ & 1 & 0.008 & 1369.1 & I388.7 \\
\hline & $\mathrm{T} / \mathrm{C}-\mathrm{C} / \mathrm{C}$ & 324 (69.4\%) & $323(61.4 \%)$ & $0.70(0.54-0.91)$ & & & \\
\hline \multirow[t]{2}{*}{ Recessive } & $\mathrm{T} / \mathrm{T}-\mathrm{T} / \mathrm{C}$ & 389 (83.3\%) & 464 (88.2\%) & 1 & 0.035 & $137 \mid .8$ & 1391.4 \\
\hline & $\mathrm{C} / \mathrm{C}$ & 78 (16.7\%) & $62(11.8 \%)$ & $0.68(0.47-0.97)$ & & & \\
\hline \multirow[t]{2}{*}{ Overdominant } & $\mathrm{T} / \mathrm{T}-\mathrm{C} / \mathrm{C}$ & 221 (47.3\%) & 265 (50.4\%) & 1 & 0.280 & |375.| & 1394.7 \\
\hline & $\mathrm{T} / \mathrm{C}$ & 246 (52.7\%) & $26 \mid(49.6 \%)$ & $0.87(0.68-1.12)$ & & & \\
\hline Log-additive & - & - & - & $0.75(0.62-0.91)$ & 0.003 & 1367.2 & 1386.8 \\
\hline
\end{tabular}

Note: *Statistically significant threshold was set at $P<0.006(0.05 / n, n=8)$ determined by Bonferroni correction.

Abbreviations: NSCLC, non-small cell lung cancer; AIC, Akaike information criterion; BIC, Bayesian information criterion.

of the SNPs between which the LD values were significant $\left(D^{\prime}>0.800\right)$ and analyzed the differences in the haplotype frequencies (frequencies greater than 3\%) between the NSCLC and control groups. The results revealed that the haplotype frequencies of the rs2853676C-rs2853677T and rs2853676C-rs2853677C SNPs significantly differed between the NSCLC and control groups $(P=0.004$ and 0.009 , respectively) after Bonferroni correction $(P<0.017)$. However, the haplotype frequencies of the rs2075786Ars2736114C-rs2736122G, rs2075786G-rs2736114C- rs $2736122 \mathrm{G}$, and rs2075786G-rs2736114T-rs2736122A were not significantly different between the NSCLC and control groups $(P>0.017)$ (Table 6).

\section{Association analysis of eight SNPs in the TERT gene with different NSCLC pathological stages}

Table 7 presents the distributions of the genotypes and alleles of the eight SNPs in the different NSCLC pathological stages (i.e., I+II and III+IV). A logistic regression analysis revealed 
Table 4 Different inheritance model analyses of rs285369I in TERT between NSCLC and control groups (after adjusting for gender and age)

\begin{tabular}{|c|c|c|c|c|c|c|c|}
\hline Models & Genotypes & $\operatorname{NSCLC~(n,~\% )~}$ & Control (n, \%) & OR $(95 \% \mathrm{CI})$ & $P$-value* & AIC & BIC \\
\hline \multirow[t]{3}{*}{ Codominant } & $\mathrm{A} / \mathrm{A}$ & 242 (5I.8\%) & $313(59.5 \%)$ & 1 & 0.003 & 1366.9 & 1391.4 \\
\hline & $\mathrm{A} / \mathrm{G}$ & $178(38.1 \%)$ & $186(35.4 \%)$ & $0.79(0.6 \mathrm{I}-1.04)$ & & & \\
\hline & $\mathrm{G} / \mathrm{G}$ & 47 (10.1\%) & $27(5.1 \%)$ & $0.45(0.27-0.74)$ & & & \\
\hline \multirow[t]{2}{*}{ Dominant } & $\mathrm{A} / \mathrm{A}$ & $242(51.8 \%)$ & $313(59.5 \%)$ & 1 & 0.011 & 1369.8 & 1389.4 \\
\hline & A/G-G/G & 225 (48.2\%) & $213(40.5 \%)$ & $0.72(0.56-0.93)$ & & & \\
\hline \multirow[t]{2}{*}{ Recessive } & A/A-A/G & 420 (89.9\%) & 499 (94.9\%) & 1 & 0.004 & 1367.7 & 1387.3 \\
\hline & $\mathrm{G} / \mathrm{G}$ & 47 (10.1\%) & $27(5.1 \%)$ & $0.49(0.30-0.80)$ & & & \\
\hline \multirow[t]{2}{*}{ Overdominant } & A/A-G/G & $289(61.9 \%)$ & $340(64.6 \%)$ & 1 & 0.300 & |375.| & 1394.8 \\
\hline & $\mathrm{A} / \mathrm{G}$ & $178(38.1 \%)$ & $186(35.4 \%)$ & $0.87(0.67-1.13)$ & & & \\
\hline Log-additive & - & - & - & $0.72(0.59-0.88)$ & 0.001 & 1366.0 & 1385.6 \\
\hline
\end{tabular}

Note: *Statistically significant threshold was set at $P<0.006(0.05 / n, n=8)$ determined by Bonferroni correction.

Abbreviations: NSCLC, non-small cell lung cancer; AIC, Akaike information criterion; BIC, Bayesian information criterion.

Table 5 Linkage disequilibrium analysis of the eight SNPs in TERT gene

\begin{tabular}{llllllll}
\hline $\boldsymbol{D}$ 'value & rs2853676 & rs2853677 & rs10069690 & rs2075786 & rs2736II4 & rs2736I22 & rs285369I \\
\hline rs2736098 & 0.437 & 0.492 & 0.237 & 0.045 & 0.250 & 0.215 & 0.145 \\
rs2853676 & - & 0.848 & 0.412 & 0.071 & 0.220 & 0.131 & 0.026 \\
rs2853677 & - & - & 0.561 & 0.095 & 0.257 & 0.248 & 0.061 \\
rs10069690 & - & - & - & 0.146 & 0.228 & 0.228 & 0.066 \\
rs2075786 & - & - & - & - & 0.898 & 0.808 & 0.109 \\
rs2736II4 & - & - & - & - & - & 0.841 & 0.217 \\
rs2736I22 & - & - & - & - & - & - & 0.359 \\
\hline
\end{tabular}

Abbreviation: SNPs, single nucleotide polymorphisms.

Table 6 Haplotype analysis of the SNPs (rs2853676-rs2853677 and rs2075786-rs2736 I 14-rs2736 I22) in TERT gene

\begin{tabular}{lllllllll}
\hline rs2853676 & rs2853677 & rs2075786 & rs2736 I I4 & rs2736 I 22 & NSCLC (n, \%) & Control (n, \%) & P-value* & OR (95\% CI) \\
\hline C & T & $I$ & $I$ & $I$ & $485.44(55.3 \%)$ & $647.98(61.6 \%)$ & 0.004 & $0.761(0.633-0.915)$ \\
C & C & $I$ & $I$ & $I$ & $224.56(25.6 \%)$ & $216.02(20.5 \%)$ & 0.009 & $1.327(1.072-1.643)$ \\
T & C & $I$ & $I$ & $I$ & $154.44(17.6 \%)$ & $168.98(16.1 \%)$ & 0.385 & $1.112(0.875-1.413)$ \\
$I$ & $I$ & A & C & G & $700.92(79.8 \%)$ & $834.98(79.4 \%)$ & 0.438 & $1.098(0.867-1.390)$ \\
$I$ & $I$ & G & C & G & $102.95(11.7 \%)$ & $124.95(11.9 \%)$ & 0.989 & $0.998(0.756-1.318)$ \\
$I$ & $I$ & G & T & A & $45.86(5.2 \%)$ & $69.65(6.6 \%)$ & 0.219 & $0.786(0.535-1.155)$ \\
\hline
\end{tabular}

Note: *Statistically significant threshold was set at $P<0.017(0.05 / n, n=3)$ determined by Bonferroni correction.

Abbreviations: SNPs, single nucleotide polymorphisms; NSCLC, non-small cell lung cancer.

that the genotypic and allelic frequencies of the eight SNPs did not significantly differ between I+II and III+IV NSCLC pathological stages after Bonferroni correction $(P>0.006)$.

\section{Association analysis of eight SNPs in the TERT gene with different NSCLC pathological types (AC and SCC)}

Table 8 presents the results of the association between the eight SNPs and different NSCLC pathological types (AC and SCC). The logistic regression analysis revealed that the genotypic and allelic distributions of the eight SNPs were not significantly different between AC and SCC.

\section{Discussion}

The progression, growth, and metastasis of tumor cells require both increased angiogenesis and increased proliferation, and these processes both depend on the maintenance of telomeres via the sustained activation of telomerase. Telomerase activity is dependent on several factors, among which the catalytic component TERT acts as a determinant of telomerase activity. ${ }^{15}$ Although the transcription of TERT is repressed in most somatic cells, the increased expression of TERT has been demonstrated to be a fundamental requirement of cellular transformation. ${ }^{30-32}$

Recently, polymorphisms in the TERT gene promoter were demonstrated to increase TERT transcription activity. ${ }^{17,18}$ 
Table 7 The association analysis between the eight SNPs in TERT and NSCLC pathological stages I+II and III+IV (after adjusting for gender and age)

\begin{tabular}{|c|c|c|c|c|c|c|c|c|c|c|}
\hline \multirow{2}{*}{$\frac{\text { SNPs }}{r s 2736098}$} & \multicolumn{3}{|c|}{ Genotypes (n, \%) } & \multirow[t]{2}{*}{$\chi^{2}$} & \multirow[t]{2}{*}{$P$-value } & \multicolumn{2}{|c|}{ Alleles (n, \%) } & \multirow[t]{2}{*}{$\chi^{2}$} & \multirow[t]{2}{*}{$P$-value* } & \multirow[t]{2}{*}{ OR (95\% CI) } \\
\hline & $\mathrm{C} / \mathrm{C}$ & $\mathrm{C} / \mathrm{T}$ & $\mathrm{T} / \mathrm{T}$ & & & C & $T$ & & & \\
\hline III+IV & $110(0.348)$ & $162(0.5 \mid 3)$ & $44(0.139)$ & 0.539 & 0.764 & $382(0.604)$ & $250(0.396)$ & 0.113 & 0.382 & $0.869(0.635-1.190)$ \\
\hline I+II & $57(0.377)$ & $72(0.477)$ & $22(0.146)$ & & & $186(0.616)$ & $116(0.384)$ & & & \\
\hline rs2853676 & $\mathrm{C} / \mathrm{C}$ & $\mathrm{C} / \mathrm{T}$ & $\mathrm{T} / \mathrm{T}$ & & & $\mathrm{C}$ & $\mathrm{T}$ & & & \\
\hline III+IV & $205(0.649)$ & $94(0.297)$ & $17(0.054)$ & 2.027 & 0.363 & $504(0.797)$ & $128(0.203)$ & 2.159 & 0.131 & $0.729(0.483-1.099)$ \\
\hline I+II & $107(0.709)$ & $39(0.258)$ & $5(0.033)$ & & & $253(0.838)$ & $49(0.162)$ & & & \\
\hline rs2853677 & $\mathrm{T} / \mathrm{T}$ & $\mathrm{T} / \mathrm{C}$ & $\mathrm{C} / \mathrm{C}$ & & & $\mathrm{T}$ & $\mathrm{C}$ & & & \\
\hline III+IV & $95(0.301)$ & $165(0.522)$ & $56(0.177)$ & 0.747 & 0.688 & $355(0.562)$ & $277(0.438)$ & 0.496 & 0.154 & $0.797(0.584-1.088)$ \\
\hline $\mathrm{I}+\mathrm{II}$ & $48(0.318)$ & $81(0.536)$ & $22(0.146)$ & & & $177(0.586)$ & $125(0.4 \mid 4)$ & & & \\
\hline rs 10069690 & $\mathrm{C} / \mathrm{C}$ & $\mathrm{C} / \mathrm{T}$ & $\mathrm{T} / \mathrm{T}$ & & & C & $\mathrm{T}$ & & & \\
\hline III+IV & $193(0.611)$ & II $2(0.354)$ & II (0.035) & 2.653 & 0.265 & $498(0.788)$ & $134(0.212)$ & 2.034 & 0.118 & $0.724(0.483-1.085)$ \\
\hline I+II & $101(0.669)$ & $48(0.318)$ & $2(0.013)$ & & & $250(0.828)$ & $52(0.172)$ & & & \\
\hline rs2075786 & $\mathrm{A} / \mathrm{A}$ & $\mathrm{A} / \mathrm{G}$ & $\mathrm{G} / \mathrm{G}$ & & & A & $\mathrm{G}$ & & & \\
\hline III+IV & $209(0.66 \mathrm{I})$ & $94(0.297)$ & $13(0.041)$ & $2.78 I$ & 0.249 & $512(0.810)$ & $120(0.190)$ & 2.755 & 0.150 & 0.73 I (0.478-I.II9) \\
\hline I+II & $110(0.728)$ & $38(0.252)$ & $3(0.020)$ & & & $258(0.854)$ & $44(0.146)$ & & & \\
\hline rs2736II4 & $\mathrm{C} / \mathrm{C}$ & $\mathrm{C} / \mathrm{T}$ & $\mathrm{T} / \mathrm{T}$ & & & $\mathrm{C}$ & $\mathrm{T}$ & & & \\
\hline III+IV & $276(0.873)$ & $38(0.120)$ & $2(0.006)$ & 2.798 & 0.247 & $590(0.934)$ & $42(0.066)$ & 2.678 & 0.153 & $0.570(0.264-1.23 I)$ \\
\hline $\mathrm{I}+\mathrm{II}$ & $139(0.921)$ & $12(0.079)$ & $0(0.000)$ & & & $290(0.960)$ & $12(0.040)$ & & & \\
\hline rs2736I22 & $\mathrm{A} / \mathrm{A}$ & $\mathrm{A} / \mathrm{G}$ & $\mathrm{G} / \mathrm{G}$ & & & A & $\mathrm{G}$ & & & \\
\hline III+IV & I (0.004) & $35(0.123)$ & $249(0.874)$ & 3.868 & 0.145 & $37(0.065)$ & $533(0.935)$ & 1.204 & 0.626 & $0.859(0.466-1.582)$ \\
\hline I+II & $4(0.023)$ & $21(0.122)$ & $147(0.855)$ & & & $29(0.084)$ & $315(0.916)$ & & & \\
\hline rs285369l & $\mathrm{A} / \mathrm{A}$ & $\mathrm{A} / \mathrm{G}$ & $\mathrm{G} / \mathrm{G}$ & & & A & G & & & \\
\hline III+IV & $166(0.525)$ & $|2|(0.383)$ & $29(0.092)$ & 0.867 & 0.648 & $453(0.717)$ & $179(0.283)$ & 0.605 & 0.445 & I.I37 (0.8I8-I.58I) \\
\hline $\mathrm{I}+\mathrm{II}$ & $76(0.503)$ & $57(0.377)$ & $18(0.119)$ & & & $209(0.692)$ & $93(0.308)$ & & & \\
\hline
\end{tabular}

Note: *Statistically significant threshold was set at $P<0.006(0.05 / n, n=8)$ determined by Bonferroni correction.

Abbreviations: SNPs, single nucleotide polymorphisms; NSCLC, non-small cell lung cancer.

Given the crucial role of TERT in the activation of telomerase, polymorphisms in the TERT gene might be associated with cancers via their effects on the expression of TERT. In 2017, Xiao and He found that rs 2736098 , which is located in exon 2, is associated with lung cancer in Chinese males. ${ }^{33} \mathrm{In}$ addition to this SNP, in the current study, we investigated the associations of seven other SNPs (i.e., rs2075786, rs 2736114 , rs10069690, rs2736098, rs2736122, rs2853676, rs2853677, and rs2853691) in the TERT gene with NSCLC in a Chinese Han population. Our results showed that rs 2853677 located in intron 2 and rs 2853691 located near the $3^{\prime}$ region of the TERT gene might be associated with NSCLC in the Chinese Han population in the current study.

In 2016, Zhou et al reported that rs2853691 in the TERT gene is associated with esophageal squamous cell carcinoma (ESCC), and they found that the A allele of rs2853691 was the protective factor of ESCC. ${ }^{23}$ In the current study, we also found that rs2853691 was associated with NSCLC susceptibility, and the A allele of rs 2853691 was the protective factor of NSCLC in the Chinese Han population. In 2010, Atzmon et al found that this SNP is associated with telomere length in Ashkenazi centenarians. ${ }^{34}$ However, in 2012, Soerensen et al reported no association between SNPs in TERT and telomere length in longevity population of the Danish population. The differences might be due to the specific population. ${ }^{35}$ Although this association has not been verified in Chinese or cancer patients, rs2853691 could be associated with NSCLC in the current population through affecting telomere length. In the future, the exploitation of this information for its applicability to assessments of lung cancer susceptibility will require additional associational and functional studies.

If a polymorphism is located in a promoter region, protein-coding region or a $3^{\prime}$ UTR region, that polymorphism might affect cancer susceptibility by affecting gene transcription, altering protein function or regulating protein yield. . $8,36,37^{-}$ However, rs 2853677 is located in the second intron at +7969 base pairs from the transcription start site of the TERT gene. Interestingly, GWAS have identified rs2853677 as a susceptibility locus for lung cancer in Japanese and African-American populations. ${ }^{20,38}$ In 2015, Campa et al demonstrated that rs2853677 is associated with pancreatic cancer susceptibility. ${ }^{39}$ Moreover, this SNP has been identified as being associated with myeloproliferative neoplasms in another study. ${ }^{40}$ In the current study, our results demonstrated 
Table 8 The association analysis between the eight SNPs in TERT and NSCLC different pathological types (after adjusting for gender and age)

\begin{tabular}{|c|c|c|c|c|c|c|c|c|c|c|}
\hline \multirow{2}{*}{$\frac{\text { SNPs }}{r s 2736098}$} & \multicolumn{3}{|c|}{ Genotypes (n, \%) } & \multirow[t]{2}{*}{$\chi^{2}$} & \multirow[t]{2}{*}{$P$-value } & \multicolumn{2}{|c|}{ Alleles (n, \%) } & \multirow[t]{2}{*}{$\chi^{2}$} & \multirow[t]{2}{*}{$P$-value* } & \multirow[t]{2}{*}{ OR $(95 \% \mathrm{Cl})$} \\
\hline & $\mathrm{C} / \mathrm{C}$ & $\mathrm{C} / \mathrm{T}$ & $\mathrm{T} / \mathrm{T}$ & & & C & $\mathrm{T}$ & & & \\
\hline $\mathrm{AC}$ & $110(0.386)$ & $130(0.456)$ & $45(0.158)$ & $5.80 \mathrm{I}$ & 0.055 & $350(0.614)$ & $220(0.386)$ & 0.079 & 0.897 & $0.982(0.746-1.293)$ \\
\hline SCC & $55(0.320)$ & $98(0.570)$ & $19(0.110)$ & & & $208(0.605)$ & $136(0.395)$ & & & \\
\hline rs2853676 & $\mathrm{C} / \mathrm{C}$ & $\mathrm{C} / \mathrm{T}$ & $\mathrm{T} / \mathrm{T}$ & & & C & $\mathrm{T}$ & & & \\
\hline $\mathrm{AC}$ & I9I (0.670) & $77(0.270)$ & $17(0.060)$ & 3.055 & 0.217 & $459(0.805)$ & $111(0.195)$ & 0.046 & 0.827 & $0.963(0.684-1.354)$ \\
\hline SCC & $\mathrm{II} 2(0.65 \mathrm{I})$ & $55(0.320)$ & $5(0.029)$ & & & $279(0.811)$ & $65(0.189)$ & & & \\
\hline rs2853677 & $\mathrm{T} / \mathrm{T}$ & $\mathrm{T} / \mathrm{C}$ & $\mathrm{C} / \mathrm{C}$ & & & $\mathrm{T}$ & C & & & \\
\hline $\mathrm{AC}$ & $86(0.302)$ & 144 (0.505) & $55(0.193)$ & 3.925 & 0.141 & $316(0.554)$ & $254(0.446)$ & 1.731 & 0.148 & $0.818(0.622-1.074)$ \\
\hline SCC & $55(0.320)$ & $96(0.558)$ & $21(0.122)$ & & & $206(0.599)$ & $138(0.401)$ & & & \\
\hline rs 10069690 & $\mathrm{C} / \mathrm{C}$ & $\mathrm{C} / \mathrm{T}$ & $\mathrm{T} / \mathrm{T}$ & & & C & $\mathrm{T}$ & & & \\
\hline $\mathrm{AC}$ & I8I (0.635) & $98(0.344)$ & $6(0.021)$ & $\mathrm{I} .567$ & 0.457 & $460(0.807)$ & $110(0.193)$ & 0.654 & 0.479 & I.I 27 (0.809-I.57I) \\
\hline SCC & $105(0.610)$ & $60(0.349)$ & $7(0.04 I)$ & & & $270(0.785)$ & $74(0.215)$ & & & \\
\hline rs2075786 & $\mathrm{A} / \mathrm{A}$ & $\mathrm{A} / \mathrm{G}$ & $\mathrm{G} / \mathrm{G}$ & & & A & G & & & \\
\hline $\mathrm{AC}$ & $196(0.688)$ & $77(0.270)$ & $12(0.042)$ & 1.509 & 0.470 & $469(0.823)$ & $101(0.177)$ & 0.011 & 0.876 & I.028 (0.723-I.464) \\
\hline SCC & $116(0.674)$ & $52(0.302)$ & $4(0.023)$ & & & $284(0.826)$ & $60(0.174)$ & & & \\
\hline rs2736II4 & $\mathrm{C} / \mathrm{C}$ & $\mathrm{C} / \mathrm{T}$ & $\mathrm{T} / \mathrm{T}$ & & & C & $\mathrm{T}$ & & & \\
\hline $\mathrm{AC}$ & $256(0.898)$ & $28(0.098)$ & I (0.004) & 0.782 & 0.676 & $540(0.947)$ & $30(0.053)$ & 0.795 & 0.352 & $0.765(0.435-1.345)$ \\
\hline SCC & $150(0.872)$ & $21(0.122)$ & I (0.006) & & & $321(0.933)$ & $23(0.067)$ & & & \\
\hline rs2736I22 & $\mathrm{A} / \mathrm{A}$ & $\mathrm{A} / \mathrm{G}$ & $\mathrm{G} / \mathrm{G}$ & & & A & G & & & \\
\hline $\mathrm{AC}$ & I (0.004) & $35(0.123)$ & $249(0.874)$ & 3.868 & 0.145 & $37(0.065)$ & $533(0.935)$ & 1.204 & 0.258 & I. $342(0.807-2.23 \mathrm{I})$ \\
\hline SCC & $4(0.023)$ & $21(0.122)$ & $147(0.855)$ & & & $29(0.084)$ & $315(0.916)$ & & & \\
\hline rs285369l & $\mathrm{A} / \mathrm{A}$ & $\mathrm{A} / \mathrm{G}$ & $\mathrm{G} / \mathrm{G}$ & & & A & $\mathrm{G}$ & & & \\
\hline $\mathrm{AC}$ & $155(0.544)$ & I0I (0.354) & $29(0.102)$ & 2.322 & 0.313 & $4 I I(0.72 I)$ & $159(0.279)$ & 1.204 & 0.323 & I.I $59(0.865-1.554)$ \\
\hline SCC & $82(0.477)$ & $73(0.424)$ & 17 (0.099) & & & $237(0.689)$ & $107(0.3 \mathrm{II})$ & & & \\
\hline
\end{tabular}

Note: *Statistically significant threshold was set at $P<0.006(0.05 / \mathrm{n}, \mathrm{n}=8)$ determined by Bonferroni correction.

Abbreviations: SNPs, single nucleotide polymorphisms; NSCLC, non-small cell lung cancer.

that the $\mathrm{T}$ allele of rs2853677 was a protective factor against NSCLC susceptibility in a Chinese Han population, which is consistent with the findings of previous studies..$^{20,38-41}$ In 2016, a study by Li et al indicated that rs2853677 is located in a functional enhancer region of TERT, which indicates that rs2853677 affects the transcription of TERT by altering the binding affinity of a transcription factor. ${ }^{41}$ These data demonstrate that rs2853677 in the TERT gene might play an important role in lung cancer via its effects on the transcription of TERT.

In 2015, Zhang et al found that the $\mathrm{C}$ allele of rs2736098 was associated with an increased risk of gastrointestinal stromal tumor. ${ }^{42}$ However, in the current study, rs2736098 exhibited no association with NSCLC in a Chinese Han population, and this finding is consistent with those of a study of hepatocellular carcinomas by Yuan et al. ${ }^{43}$ Moreover, the results related to rs $2853676,{ }^{44,45} \mathrm{rs} 10069690,{ }^{46,47} \mathrm{rs} 2075786,{ }^{48,49}$ and rs $2736122^{21,50}$ have exhibited inconsistencies in different studies (including the current study). The reasons for these inconsistencies could be related to the different diseases studied and different genetic backgrounds of the studied populations. In the current study, we also investigated the associations of these SNPs with the different pathological stages and types. However, the results revealed that none of the SNPs were associated with the pathological stages and types of NSCLC in the current population.

\section{Conclusion}

Studies have demonstrated that TERT might play a special role in cancer development and could represent another molecular target for cancer diagnosis and/or therapy. In the current study, we observed that the T allele of rs2853677 and the A allele of rs 2853691 in the TERT gene might be protective factors against NSCLC in a Chinese Han population. The statistical power of rs2853677 and rs285369 were 0.815 and 0.898 calculated by "Power and Sample Size" program. ${ }^{29}$ However, one limitation that might have affected the results of the association study was the lack of smoking status data of the control individuals. This limitation made it difficult to perform a gene-smoking interaction analysis in the current study. In the future, larger scale samples and systemic reviews would be helpful for clarifying the associations of the variations in the TERT gene with NSCLC. Moreover, further combining the functional research would promote the diagnostic and therapeutic applications of targeting the TERT gene in NSCLC. 


\section{Acknowledgments}

We express our gratitude for the participation of the patients and control subjects in this study. This work was supported by grants from the National Natural Science Foundation of China (81573206 and 31270030), Yunnan Applied Basic Research Projects (2016FA034), Fundamental Research Funds for the Central Universities and the PUMC Youth Fund (3332015149), The Association Foundation Program of Yunnan Provincial Science and Technology Department and Kunming Medical University (2017FE468-193), and Special Funds for high-level health talents of Yunnan Province (D-201669 and L-201615). The funders had no role in study design, data collection and analysis, decision to publish, or preparation of the manuscript.

\section{Disclosure}

The authors report no conflicts of interest in this work.

\section{References}

1. Jemal A, Bray F, Center MM, et al. Global cancer statistics. CA Cancer J Clin. 2011;61(2):69-90.

2. Molina JR, Yang P, Cassivi SD, Schild SE, Adjei AA. Non-small cell lung cancer: epidemiology, risk factors, treatment, and survivorship. Mayo Clin Proc. 2008;83(5):584-594.

3. Johnson JL, Pillai S, Chellappan SP. Genetic and biochemical alterations in non-small cell lung cancer. Biochem Res Int. 2012;2012:940405.

4. Hsiung CA, Lan Q, Hong YC, et al. The $5 \mathrm{p} 15.33$ locus is associated with risk of lung adenocarcinoma in never-smoking females in Asia. PLoS Genet. 2010;6(8). pii: e1001051.

5. Hu Z, Wu C, Shi Y, et al. A genome-wide association study identifies two new lung cancer susceptibility loci at 13q12.12 and 22q12.2 in Han Chinese. Nat Genet. 2011;43(8):792-796.

6. Wang Y, McKay JD, Rafnar T, et al. Rare variants of large effect in BRCA2 and CHEK2 affect risk of lung cancer. 2014;46(7):736-741.

7. Blasco MA. Mammalian telomeres and telomerase: why they matter for cancer and aging. Eur J Cell Biol. 2003;82(9):441-446.

8. Jiang H, Ju Z, Rudolph KL. Telomere shortening and ageing. Z Gerontol Geriatr. 2007;40(5):314-324.

9. Epel ES, Blackburn EH, Lin J, et al. Accelerated telomere shortening in response to life stress. Proc Natl Acad Sci U S A. 2004;101(49): 17312-17315.

10. Masutomi K, Yu EY, Khurts S, et al. Telomerase maintains telomere structure in normal human cells. Cell. 2003;114(2):241-253.

11. Collins K, Mitchell JR. Telomerase in the human organism. Oncogene. 2002;21(4):564-579.

12. Low KC, Tergaonkar V. Telomerase: central regulator of all of the hallmarks of cancer. Trends Biochem Sci. 2013;38(9):426-434.

13. Shay JW, Bacchetti S. A survey of telomerase activity in human cancer. Eur J Cancer. 1997;33(5):787-791.

14. Shay JW, Zou Y, Hiyama E, Wright WE. Telomerase and cancer. Hum Mol Genet. 2001;10(7):677-685.

15. Xu L, Li S, Stohr BA. The role of telomere biology in cancer. Annu Rev Pathol. 2013;8:49-78.

16. Hahn WC, Counter CM, Lundberg AS, et al. Creation of human tumour cells with defined genetic elements. Nature. 1999;400(6743):464-468.

17. Huang FW, Hodis E, Xu MJ, et al. Highly recurrent TERT promoter mutations in human melanoma. Science. 2013;339(6122):957-959.

18. Horn S, Figl A, Rachakonda PS, et al. TERT promoter mutations in familial and sporadic melanoma. Science. 2013;339(6122):959-961.
19. Nan H, Qureshi AA, Prescott J, De Vivo I, Han J. Genetic variants in telomere-maintaining genes and skin cancer risk. Hum Genet. 2011;129(3):247-253.

20. Shiraishi K, Kunitoh H, Daigo Y, et al. A genome-wide association study identifies two new susceptibility loci for lung adenocarcinoma in the Japanese population. Nat Genet. 2012;44(8):900-903.

21. Hofer P, Baierl A, Bernhart K, et al. Association of genetic variants of human telomerase with colorectal polyps and colorectal cancer risk. Mol Carcinog. 2012;51 Suppl 1:E176-182.

22. Shen J, Gammon MD, Terry MB, et al. Genetic polymorphisms in telomere pathway genes, telomere length, and breast cancer survival. Breast Cancer Res Treat. 2012;134(1):393-400.

23. Zhou L, Fu G, Wei J, et al. The identification of two regulatory ESCC susceptibility genetic variants in the TERT-CLPTM1L loci. Oncotarget. 2016;7(5):5495-5506.

24. Groome PA, Bolejack V, Crowley JJ, et al. The IASLC Lung Cancer Staging Project: validation of the proposals for revision of the T, N, and $\mathrm{M}$ descriptors and consequent stage groupings in the forthcoming (seventh) edition of the TNM classification of malignant tumours. J Thorac Oncol. 2007;2(8):694-705.

25. Beasley MB, Brambilla E, Travis WD. The 2004 World Health Organization classification of lung tumors. Semin Roentgenol. 2005;40(2):90-97.

26. Shi YY, He L. SHEsis, a powerful software platform for analyses of linkage disequilibrium, haplotype construction, and genetic association at polymorphism loci. Cell Res. 2005;15(2):97-98.

27. Li Z, Zhang Z, He Z, et al. A partition-ligation-combination-subdivision EM algorithm for haplotype inference with multiallelic markers: update of the SHEsis (http://analysis.bio-x.cn). Cell Res. 2009;19(4):519-523.

28. Sole X, Guino E, Valls J, Iniesta R, Moreno V. SNPStats: a web tool for the analysis of association studies. Bioinformatics. 2006;22(15):1928-1929.

29. Dupont WD, Plummer WD Jr. Power and sample size calculations for studies involving linear regression. Control Clin Trials. 1998;19(6):589-601.

30. Cong YS, Wright WE, Shay JW. Human telomerase and its regulation. Microbiol Mol Biol Rev. 2002;66(3):407-425.

31. Kolquist KA, Ellisen LW, Counter CM, et al. Expression of TERT in early premalignant lesions and a subset of cells in normal tissues. Nat Genet. 1998;19(2):182-186.

32. Hiyama E, Hiyama K. Telomere and telomerase in stem cells. $\mathrm{Br} J$ Cancer. 2007;96(7):1020-1024

33. Xiao X, He W. Genetic polymorphisms in the TERT-CLPTM1L region and lung cancer susceptibility in Chinese males. Oncol Lett. 2017;14(2):1588-1594.

34. Atzmon G, Cho M, Cawthon RM, et al. Evolution in health and medicine Sackler colloquium: Genetic variation in human telomerase is associated with telomere length in Ashkenazi centenarians. Proc Natl Acad Sci U $S$ A. 2010;107 Suppl 1:1710-1717.

35. Soerensen M, Thinggaard M, Nygaard M, et al. Genetic variation in TERT and TERC and human leukocyte telomere length and longevity: a cross-sectional and longitudinal analysis. Aging Cell. 2012;11(2): 223-227.

36. Bond GL, Hu W, Bond EE, et al. A single nucleotide polymorphism in the MDM2 promoter attenuates the $\mathrm{p} 53$ tumor suppressor pathway and accelerates tumor formation in humans. Cell. 2004;119(5):591-602.

37. Ryan BM, Robles AI, McClary AC, et al. Identification of a functional SNP in the 3'UTR of CXCR2 that is associated with reduced risk of lung cancer. Cancer Res. 2015;75(3):566-575.

38. Zanetti KA, Wang Z, Aldrich M, et al. Genome-wide association study confirms lung cancer susceptibility loci on chromosomes $5 \mathrm{p} 15$ and $15 q 25$ in an African-American population. Lung Cancer. 2016;98:33-42.

39. Campa D, Rizzato C, Stolzenberg-Solomon R, et al. TERT gene harbors multiple variants associated with pancreatic cancer susceptibility. Int J Cancer. 2015;137(9):2175-2183.

40. Hinds DA, Barnholt KE, Mesa RA, et al. Germ line variants predispose to both JAK2 V617F clonal hematopoiesis and myeloproliferative neoplasms. Blood. 2016;128(8):1121-1128. 
41. Li X, Xu X, Fang J, et al. Rs2853677 modulates Snail1 binding to the TERT enhancer and affects lung adenocarcinoma susceptibility. Oncotarget. 2016;7(25):37825-37838.

42. Zhang R, Zhao J, Xu J, et al. Genetic variations in the TERT and CLPTM1L gene region and gastrointestinal stromal tumors risk. Oncotarget. 2015;6(31):31360-31367.

43. Yuan X, Cheng G, Yu J, et al. The TERT promoter mutation incidence is modified by germline TERT rs2736098 and rs2736100 polymorphisms in hepatocellular carcinoma. Oncotarget. 2017;8(14):23120-23129.

44. Zheng Y, Ogundiran TO, Adebamowo C, et al. Lack of association between common single nucleotide polymorphisms in the TERTCLPTM1L locus and breast cancer in women of African ancestry. Breast Cancer Res Treat. 2012;132(1):341-345.

45. He X, Wei Y, Chen Z, et al. TERT rs 2853676 polymorphisms correlate with glioma prognosis in Chinese population. Oncotarget. 2016;7(45): 73781-73791.
46. Chen S, Wang Q, Wu CY, et al. A single-nucleotide polymorphism of CCL21 rs951005 T>C is associated with susceptibility of polymyositis and such patients with interstitial lung disease in a Chinese Han population. Clin Exp Rheumatol. 2015;33(5):639-646.

47. Cerhan JR, Slager SL. Familial predisposition and genetic risk factors for lymphoma. Blood. 2015;126(20):2265-2273.

48. Ter-Minassian M, Wang Z, Asomaning K, et al. Genetic associations with sporadic neuroendocrine tumor risk. Carcinogenesis 2011;32(8):1216-1222.

49. Hosgood HD 3rd, Cawthon R, He X, Chanock S, Lan Q. Genetic variation in telomere maintenance genes, telomere length, and lung cancer susceptibility. Lung Cancer. 2009;66(2):157-161.

50. Carvajal-Carmona LG, O'Mara TA, Painter JN, et al. Candidate locus analysis of the TERT-CLPTM1L cancer risk region on chromosome 5 p15 identifies multiple independent variants associated with endometrial cancer risk. Hum Genet. 2015;134(2):231-245.
Cancer Management and Research

\section{Publish your work in this journal}

Cancer Management and Research is an international, peer-reviewed open access journal focusing on cancer research and the optimal use of preventative and integrated treatment interventions to achieve improved outcomes, enhanced survival and quality of life for the cancer patient The manuscript management system is completely online and includes

\section{Dovepress}

a very quick and fair peer-review system, which is all easy to use. Visit http://www.dovepress.com/testimonials.php to read real quotes from published authors. 